\title{
Roles of Endothelin-1 and Nitric Oxide in the Mechanism for Ethanol-induced Vasoconstriction in Rat Liver
}

\author{
Masahide Oshita, Yoshiyuki Takei, Sunao Kawano, Harumasa Yoshihara, Taizo Hijioka, Hiroyuki Fukui, \\ Moritaka Goto, Eiji Masuda, Yoshiya Nishimura, Hideyuki Fusamoto, and Takenobu Kamada \\ The First Department of Medicine, Osaka University Medical School, Osaka 553, Japan
}

\begin{abstract}
This study was designed to investigate the mechanism for ethanol-induced hepatic vasoconstriction in isolated perfused rat liver. Upon initiation of ethanol infusion into the portal vein at concentrations ranging from 25 to $100 \mathrm{mM}$, portal pressure began to increase in a concentration-dependent manner and reached maximal levels in 2-5 min (initial phase), followed by a gradual decrease over the period of ethanol infusion (escape phenomenon). Endothelin-1 antiserum significantly inhibited this ethanol-induced hepatic vasoconstriction by $45-80 \%$. Cessation of infusion of endothelin-1 antiserum was followed by a subsequent increase in portal pressure. On the other hand, when a nitric oxide synthesis inhibitor, $\boldsymbol{N}^{\mathbf{G}}$-monomethyl-L-arginine (L-NMMA), was infused into the portal vein simultaneously with ethanol, the initial phase of the response of portal pressure to ethanol was not altered and the peak values of portal pressure remained unchanged. However, after the peak increase in portal pressure, the rate of decrease was less than in the absence of L-NMMA. Thus, L-NMMA diminished the escape phenomenon and sustained the vasoconstriction. This study supports the hypothesis that two endothelium-derived vasoactive factors, endothelin-1 and nitric oxide, regulate hepatic vascular tone in the presence of ethanol. (J. Clin. Invest. 1993. 91:1337-1342.) Key words: ethanol-induced vasoconstriction • liver • endothelin-1 • nitric oxide
\end{abstract}

\section{Introduction}

Ethanol causes serious health problems (1) including ethanolinduced microcirculatory disturbances in many organs such as heart and brain (2-4). In the liver, infusion of ethanol into the portal vein elicits vasoconstriction in the hepatic microvasculature, leading to hepatic tissue hypoxia and eventually hepatocellular necrosis $(5,6)$. French et al. reported that ethanol-induced perturbation of microcirculation plays an important role in the pathogenesis of alcoholic liver damage (7-10). Accordingly, a method to inhibit this vasoconstrictive effect of ethanol would be expected to effectively reduce the incidence

Preliminary reports of portions of this work were presented at the 42nd Annual Meeting of the American Association for the Study of Liver Disease, Chicago, IL, 2-5 November 1991.

Address correspondence to Dr. Masahide Oshita, The First Department of Medicine, Osaka University Medical School, 1-1-50 Fukushima, Fukushima-ku, Osaka 553, Japan.

Received for publication 5 June 1992 and in revised form 26 October 1992.

J. Clin. Invest.

(c) The American Society for Clinical Investigation, Inc.

$0021-9738 / 93 / 04 / 1337 / 06 \$ 2.00$

Volume 91, April 1993, 1337-1342 and morbidity of alcoholic liver damage. However, the mechanism for the vasoactive effect of ethanol is unknown.

Recently, a potent vasoactive peptide, endothelin (11), was shown to produce sustained vasoconstriction in the liver (12, 13). This endothelin-induced vasoconstriction might be related to contraction of Ito cells (14). On the other hand, sodium nitroprusside, which yields nitric oxide (15), diminished vasoconstriction induced by ethanol in perfused rat liver ( 5 , $6)$. Moreover, interaction between endothelin and nitric oxide has been reported to be of importance in regulation of vascular tone (16-19). These data led us to hypothesize that these endothelium-derived vasoactive factors, endothelin and nitric oxide, participate in regulation of microvascular tone of the liver in the presence of ethanol. To test this hypothesis, we examined the effect of endothelin-1 antiserum and an inhibitor of nitric oxide synthesis, $N^{\mathrm{G}}$-monomethyl-L-arginine (L-NMMA) ${ }^{1}$ (20), on changes in portal pressure, an indicator of hepatic microvascular tone in isolated perfused rat liver.

\section{Methods}

Experimental animals. All animal experiments were conducted in accordance with local institutional guidelines for the care and use of laboratory animals. Male Sprague-Dawley rats $(250-300 \mathrm{~g})$ were used in this study. They were provided with water and standard laboratory chow ad lib.

Chemicals. Endothelin-1 antiserum (14198-v, lot No. 891-400518) was purchased from the Peptide Institute (Osaka, Japan). In a sensitivity test, this antiserum showed an $\mathrm{IC}_{50}$ of $1.0 \mathrm{pmol} / \mathrm{ml}$ at $1: 20,000$ dilution. This antiserum was reconstituted in phosphate buffer. This preparation of antiserum has $100 \%$ crossreactivity with human/rat endothelin-1. An inhibitor of nitric oxide synthesis, L-NMMA, was purchased from Sigma Chemical Co. (St. Louis, MO).

Nonrecirculating liver perfusion. Fed rats were anesthetized with sodium pentobarbital $(45 \mathrm{mg} / \mathrm{kg}$ i.p.). Livers were isolated and per-

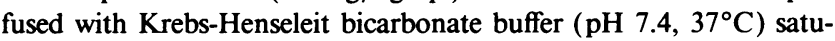
rated with $95 \% \mathrm{O}_{2} / 5 \% \mathrm{CO}_{2}$ in a hemoglobin-free, nonrecirculating system at a constant flow rate $(36 \mathrm{ml} / \mathrm{min})(21)$. Perfusate was pumped with a rotor pump ( Taiyo Scientific Industrial Co., Tokyo, Japan) into the liver via a cannula inserted in the portal vein. The effluent perfusate was collected with a cannula placed in the vena cava. Ethanol was mixed with the perfusate at final concentrations just before infusion with a continuous infusion pump (Atom Co., Tokyo, Japan). Various dilutions of endothelin-1 antiserum were infused with ethanol for 10 min after the initiation of ethanol infusion. An inhibitor of nitric oxide synthesis, L-NMMA, was infused from $10 \mathrm{~min}$ before the initiation of ethanol infusion to the end of ethanol infusion.

Portal pressure. Portal pressure was monitored continuously by measuring the height of perfusate in an open vertical capillary column (i.d. $=2 \mathrm{~mm}$ ) attached to the perfusion system just before the inflow cannula when perfusate was infused at a constant flow rate $(36 \mathrm{ml} /$ $\min )(5,6)$. The column was calibrated for baseline pressure at the end

1. Abbreviation used in this paper: L-NMMA, $N^{\mathrm{G}}$-monomethyl-L-arginine. 
of each experiment by the fluid level in the capillary when perfusate was pumped through the influent cannula in the absence of liver at the same flow rate used with tissue.

Statistics. Results are expressed as means \pm SEM unless otherwise indicated. Statistical analysis was performed using an analysis of variance analysis. $P$ values less than 0.05 were considered statistically significant.

\section{Results}

Effect of ethanol on portal pressure in perfused rat liver. Portal pressure under control conditions in which no ethanol was infused was $6.0 \pm 0.3 \mathrm{cmH}_{2} \mathrm{O}$. Upon the initiation of ethanol infusion into the liver at concentrations $>25 \mathrm{mM}$, portal pressure began to increase in a concentration-dependent manner and reached maximal levels in 2-5 min (initial phase), followed by a gradual decrease over the period of ethanol infusion (escape phenomenon) (Fig. $1 A$ ). However, portal pressure remained at levels higher than the basal value throughout the period of ethanol infusion (Fig. $1 A$ ). The maximal value of change in portal pressure increased in a dose-dependent fashion. The degree of vasoconstriction was represented by change in portal pressure averaged over $10 \mathrm{~min}$ (the 10 -min period after initiation of ethanol infusion ). This was calculated from the area under the curve of the change in portal pressure divided by the perfusion time ( $10 \mathrm{~min})$. Higher concentrations of ethanol ( $\geq 25 \mathrm{mM}$ ) increased the change in portal pressure averaged over $10 \mathrm{~min}$ in a concentration-dependent manner, but $10 \mathrm{mM}$ ethanol did not cause any change in portal pressure (Fig. $1 B$ ).

Effect of endothelin-1 antiserum on ethanol-induced hepatic vasoconstriction. When $100 \mathrm{mM}$ ethanol was infused into the liver simultaneously with various dilutions of endothelin-1 antiserum ranging from $1: 3.6 \times 10^{3}$ to $1: 72.0 \times 10^{3}$, the increase in portal pressure was attenuated and was significantly smaller than in the absence of endothelin-1 antiserum (Fig. $2 A$ ): 1:3.6 $\times 10^{3}$ or $1: 7.2 \times 10^{3}$ diluted endothelin-1 antiserum decreased the peak value of portal pressure significantly $(15.4 \pm 8.1$ and $21.8 \pm 6.8 \mathrm{mmH}_{2} \mathrm{O}$ vs. $55.7 \pm 14.0 \mathrm{mmH}_{2} \mathrm{O}, P<0.05$, respectively). Furthermore, infusion of $1: 3.6 \times 10^{3}, 1: 7.2 \times 10^{3}$ or $1: 14.4 \times 10^{3}$ diluted antiserum significantly inhibited the change in portal pressure averaged over $10 \mathrm{~min}$ of ethanol infusion by $45-80 \%$ (Fig. $2 \mathrm{~B}$ ). Infusion of endothelin-1 antiserum at $1: 14.4 \times 10^{3}$ dilution also significantly reduced the increase in portal pressure induced by ethanol at concentrations of 25 or $50 \mathrm{mM}$ (Fig. 3). On the other hand, endothelin-1 antiserum did not affect portal pressure in the absence of ethanol (Fig. 3).

Effect of L-NMMA on ethanol-induced increases in portal pressure. When a nitric oxide synthesis inhibitor, L-NMMA, was infused into the portal vein simultaneously with ethanol $(100 \mathrm{mM})$, the initial phase of the response of portal pressure to ethanol was not altered and the peak values of portal pressure remained unchanged (Fig. $4 A$ ). However, after the peak increase in portal pressure, the rate of decrease was less than in the absence of L-NMMA; i.e., L-NMMA diminished the escape phenomenon and sustained the vasoconstriction (Fig. 4 $A$ ). Furthermore, when L-NMMA infusion was discontinued after $10 \mathrm{~min}$ of ethanol infusion, portal pressure began to decrease at a greater rate than control, approaching the basal level (Fig. $4 \mathrm{~B}$ ). L-NMMA at concentrations $>10 \mu \mathrm{M}$ significantly enhanced the increase in portal pressure induced by $100 \mathrm{mM}$ ethanol (Fig. $4 C$ ). Infusion of L-NMMA at $10 \mu \mathrm{M}$ enhanced
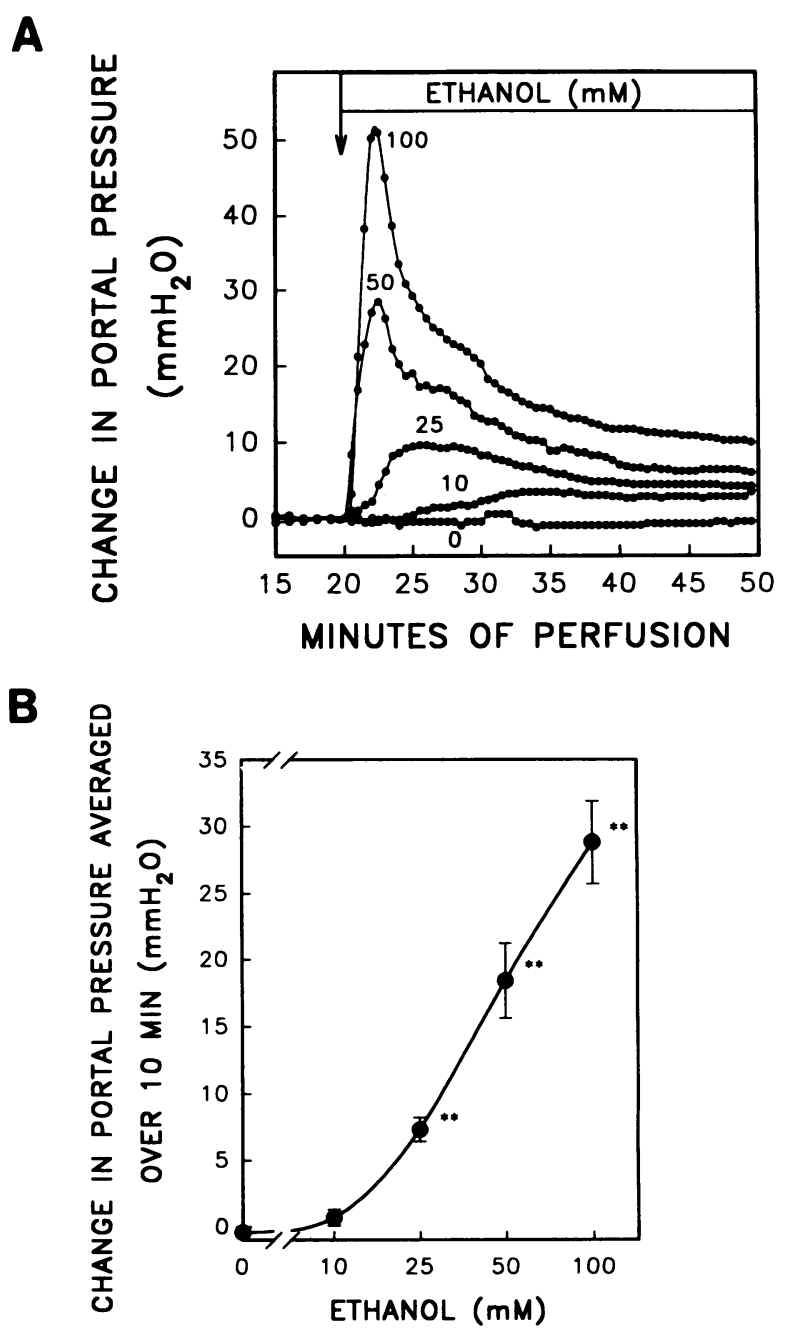

Figure 1. $(A)$ Time course of ethanol-induced change in portal pressure in the isolated perfused rat liver. Livers from fed rats were isolated and perfused with Krebs-Henseleit bicarbonate buffer ( $\mathrm{pH} 7.4$, $37^{\circ} \mathrm{C}$ ) saturated with $95 \% \mathrm{O}_{2} / 5 \% \mathrm{CO}_{2}$ in a hemoglobin-free, nonrecirculating system at a constant flow rate $(36 \mathrm{ml} / \mathrm{min})$. Portal pressure was monitored continuously. Ethanol was infused into the influent at a concentration of $0,10,25,50$, or $100 \mathrm{mM}$. Values indicate mean from five rats. $(B)$ Effect of ethanol on portal pressure in the isolated perfused rat liver. Change in portal pressure averaged over $10 \mathrm{~min}$ of ethanol infusion (the 10-min period after initiation of ethanol infusion), which is an index of the degree of ethanol-induced hepatic vasoconstriction, was calculated. Values indicate mean \pm SEM from five rats. ${ }^{* *} P<0.01$ compared with values in the absence of ethanol.

the increase in portal pressure induced by ethanol at concentrations $<100 \mathrm{mM}$ (Fig. 5). Moreover, changes in portal pressure after $30 \mathrm{~min}$ of ethanol infusion at concentrations $\geq 10 \mathrm{mM}$ were about two times higher in the presence of L-NMMA than in its absence ( Table I). It is notable that L-NMMA elicited an increase in portal pressure when ethanol was present at $10 \mathrm{mM}$, a concentration at which ethanol caused no visible change in portal pressure (Figs. 5 and 6). On the other hand, L-NMMA did not affect portal pressure in the absence of ethanol (Fig. 5 ).

\section{Discussion}

In this study, ethanol at concentrations of $25 \mathrm{mM}$ or higher elevated portal pressure in a concentration-dependent fashion 

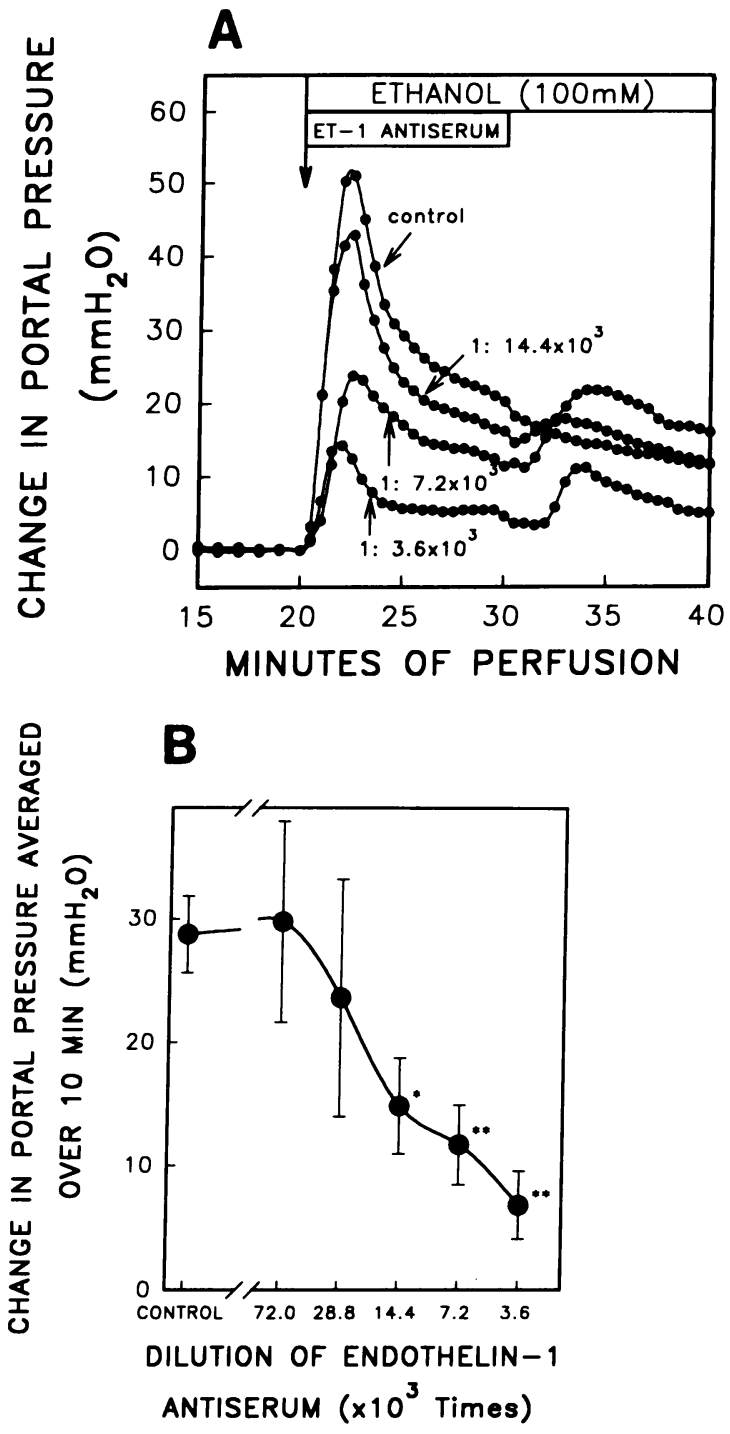

Figure 2. $(A)$ Time course of change in portal pressure during ethanol $(100 \mathrm{mM})$ infusion in the presence and absence of endothelin- 1 antiserum. Conditions are as described in Fig. $1 \mathrm{~A}$. Endothelin-1 antiserum, at $1: 3.6 \times 10^{3}, 1: 7.2 \times 10^{3}$, or $1: 14.4 \times 10^{3}$ dilution, was infused with ethanol for $10 \mathrm{~min}$ as indicated by the horizontal bar and arrow. Values indicate mean from five rats. $(B)$ Concentration response of endothelin-1 antiserum on ethanol-induced increase in portal pressure. Conditions are as described in Fig. $1 \mathrm{~A}$. Endothelin-1 antiserum, ranging from 1:3.6 $\times 10^{3}$ to $1: 72.0 \times 10^{3}$ dilution, was infused into the influent together with ethanol $(100 \mathrm{mM})$. Change in portal pressure averaged during infusion of ethanol and endothelin-1 antiserum (over $10 \mathrm{~min}$ ) was calculated. Values indicate means \pm SEM from five rats. ${ }^{*} P<0.05 ;{ }^{* *} P<0.01$ compared with values in the absence of endothelin- 1 antiserum.

(Fig. 1, $A$ and $B$ ) with the peak increase occurring 2-5 min after onset of ethanol infusion. When ethanol was infused into the liver simultaneously with endothelin-1 antiserum, the increase in portal pressure in the presence of endothelin-1 antiserum was significantly smaller than in its absence (Figs. 2, $A$ and $B$, and 3 ). Moreover, cessation of infusion of endothelin-1 antiserum was followed by a subsequent increase in portal pressure (Fig. $2 A$ ). These data indicate that the vasoconstrictive effect of ethanol on the liver was predominantly mediated by endothelin-1.
In contrast to the effect of anti-endothelin-1 treatment, LNMMA, which blocks synthesis of nitric oxide from L-arginine (20), did not affect the initial phase of portal pressure in response to ethanol infusion and the peak values of portal pressure remained unchanged. L-NMMA, however, sustained vasoconstriction, resulting in a weakened "escape phenomenon" (Fig. $4 A$ ), evidenced by the fact that change in portal pressure averaged over $10 \mathrm{~min}$ of ethanol infusion was significantly higher in the presence of L-NMMA than in its absence (Fig. 4 $C)$. These data suggest that nitric oxide participates in the escape phenomenon during ethanol load by acting as a vasodilator after the peak increase of portal pressure.

Based on the above observations, a likely sequence of events after ethanol administration into the portal vein is as follows: upon initiation of ethanol infusion at concentrations $>25 \mathrm{mM}$, endothelin-1 elicits vasoconstriction in the hepatic vasculature, resulting in a rapid increase in portal pressure (initial phase). After the portal pressure has reached its maximal level, nitric oxide acts as a vasodilator and causes portal pressure to decrease gradually and reach a new steady state in 20 30 min of ethanol infusion (escape phenomenon). This new steady state appears to be determined by the balance between the degree of vasoconstriction induced by ethanol and action of nitric oxide since infusion of L-NMMA shifted the steady-state pressure after ethanol infusion upward (Table I).

The origin of endothelin-1 was not determined in this study. However, it seems reasonable to postulate that sinusoidal endothelial cells are responsible for synthesis of endothelin1 since it has recently been shown that ethanol stimulates immunoreactive endothelin-1 release from cultured human umbilical vein endothelial cells (22). In addition, hepatic sinusoidal endothelial cells release endothelin in response to transforming growth factor $\beta(23)$. On the other hand, the site

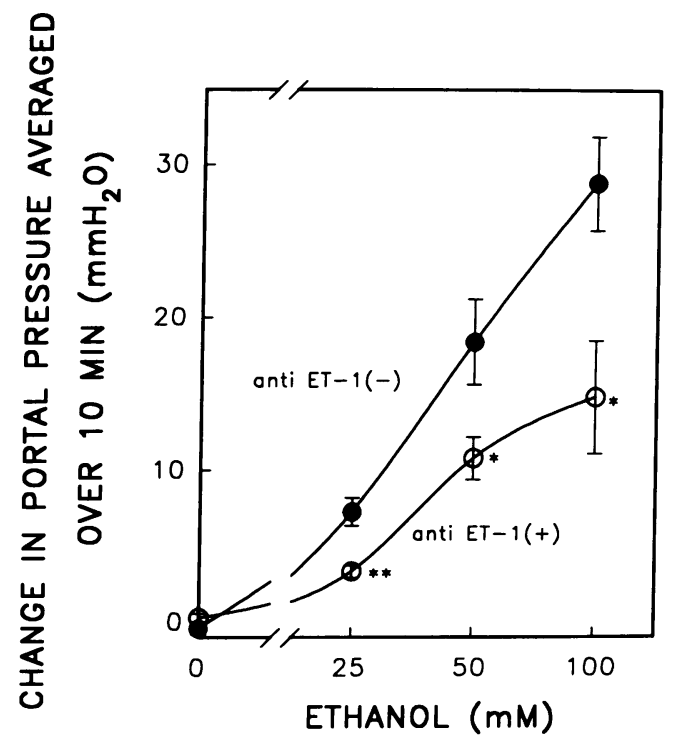

Figure 3. Effect of endothelin-1 antiserum on ethanol-induced increase in portal pressure. Conditions are as described in Fig. $1 \mathrm{~A}$. Endothelin- 1 antiserum at 1:14.4 $\times 10^{3}$ dilution was infused with ethanol at a concentration of $0,25,50$, or $100 \mathrm{mM}$, for $10 \mathrm{~min}$ after the initiation of ethanol infusion. Change in portal pressure averaged over $10 \mathrm{~min}$ of ethanol infusion was calculated. Values indicate means \pm SEM from five rats. ${ }^{*} P<0.05 ;{ }^{* *} P<0.01$ compared with values in the absence of endothelin-1 antiserum. 

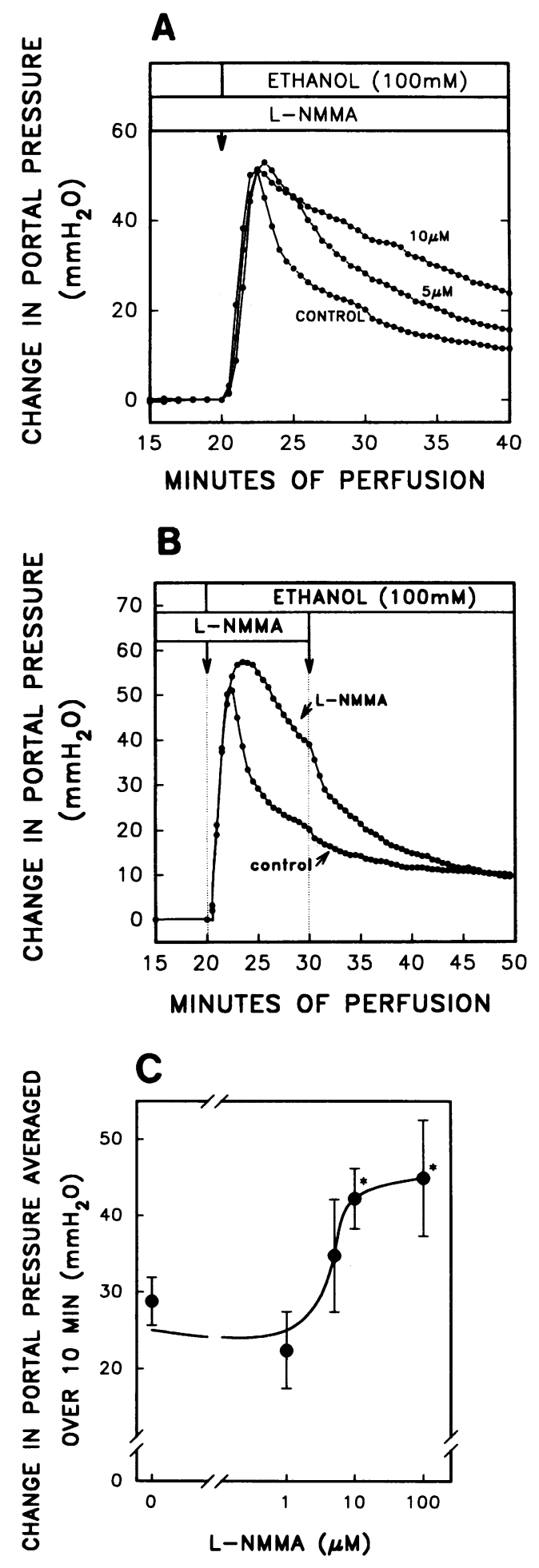

Figure 4. Effect of L-NMMA on change in portal pressure during ethanol infusion. Conditions are as described in Fig. $1 A$. $(A) \mathrm{L}-$ NMMA, at a concentration of either 5 or $10 \mu \mathrm{M}$, was infused with ethanol $(100 \mathrm{mM})$ from $10 \mathrm{~min}$ before the initiation to the end of ethanol infusion. Values indicate mean from five rats. (B) $100 \mu \mathrm{M}$ L-NMMA was infused for 20 min beginning 10 min before initiation of ethanol ( $100 \mathrm{mM}$ ) infusion. L-NMMA infusion was discontinued at $10 \mathrm{~min}$ after initiation of ethanol infusion. Values indicate mean from five rats. $(C)$ Concentration response curve of L-NMMA on increase in portal pressure induced by $100 \mathrm{mM}$ ethanol. Conditions are as described in Fig. $1 A$. L-NMMA, at concentrations ranging from 1

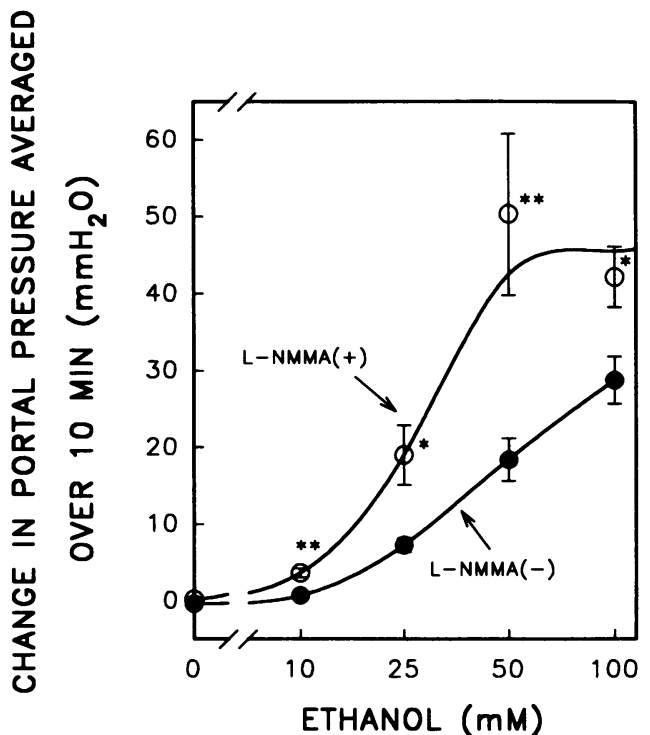

Figure 5. Effect of L-NMMA on increase in portal pressure induced by various concentrations of ethanol. Conditions are as described in Fig. $1 A .10 \mu \mathrm{M}$ L-NMMA was infused with ethanol at a concentration of $0,10,25,50$, or $100 \mathrm{mM}$ from $10 \mathrm{~min}$ before the initiation to the end of ethanol infusion. Change in portal pressure averaged over $10 \mathrm{~min}$ of ethanol infusion was calculated. Values indicate means \pm SEM from five rats. ${ }^{*} P<0.05 ;{ }^{*} P<0.01$ compared with values in the absence of L-NMMA.

at which ET-1 exerts vasoconstrictive action remains in question, although early studies by Hijioka et al. suggest that ethanol elicits a vasoconstrictive effect on hepatic vasculature at the presinusoidal and sinusoidal regions (24). The sinusoidal endothelium and Ito cells might be possible candidates responsible for the endothelin-1-induced constriction of the sinusoids because both cell types contain contractile proteins $(25,26)$. In particular, Ito cells were shown recently to contract when endothelin-1 was added in vitro $(14,27)$, suggesting a role for Ito cells in the regulation of hepatic microcirculation. On the other hand, nitric oxide has been reported to be synthesized by hepatocytes (28). However, the precise mechanism by which ethanol causes nitric oxide release and the site(s) on which nitric oxide acts in the presence of ethanol remain to be elucidated.

To date, reports conflict over the effect of ethanol on hepatic hemodynamics (29-33). Previous studies by several investigators indicated increases in portal pressure $(29,30)$, whereas others indicated no effect $(31-33)$. We have also shown in a recent report that ethanol at concentrations ranging from 25 to $400 \mathrm{mM}$ caused hepatic vasoconstriction (5). The reason for this discrepancy is not clear; however, differences in ethanol concentrations used are probably responsible since ethanol at a lower concentration $(10 \mathrm{mM})$ failed to elicit any noticeable vasoactive effects (Fig. $1, A$ and $B$ ).

This study demonstrates that simultaneous infusion of $\mathrm{L}$ NMMA and ethanol (10 $\mathrm{mM}$ ) elevated the portal pressure

to $100 \mu \mathrm{M}$, was infused into the influent together with ethanol ( 100 $\mathrm{mM}$ ). Change in portal pressure averaged during infusion of ethanol and L-NMMA (over $10 \mathrm{~min}$ ) was calculated. Values indicate means \pm SEM from five rats. ${ }^{*} P<0.05$ compared with values in the absence of L-NMMA. 
Table 1. Effect of Ethanol Concentration on the Steady-State Portal Pressure in the Presence and Absence of L-NMMA

\begin{tabular}{ccc}
\hline & \multicolumn{2}{c}{ Change in portal pressure } \\
\cline { 2 - 3 } Ethanol \\
concentration & Ethanol & Ethanol + L-NMMA \\
\hline$m M$ & \multicolumn{3}{c}{$m^{2} \mathrm{H}_{2} \mathrm{O}$} \\
0 & $-0.5 \pm 1.2$ & $-0.7 \pm 0.9$ \\
10 & $2.8 \pm 0.6$ & $6.8 \pm 1.2^{*}$ \\
25 & $4.2 \pm 1.0$ & $8.2 \pm 1.2^{*}$ \\
50 & $7.0 \pm 1.7$ & $17.2 \pm 3.6^{*}$ \\
100 & $9.8 \pm 0.7$ & $18.2 \pm 1.2^{\ddagger}$ \\
\hline
\end{tabular}

Conditions are described in Fig. 1. When ethanol was infused into the liver, the portal pressure increased to its maximal level, decreased gradually, and reached a new steady state 20-30 min after the initiation of ethanol infusion in the absence and presence of $10 \mu \mathrm{M} \mathrm{L}$ NMMA. Values indicate change in portal pressure $30 \mathrm{~min}$ after the initiation of ethanol infusion and show means \pm SEM from five rats. ${ }^{*} P<0.05 ;{ }^{\ddagger} P<0.01$ compared with values in the absence of $L$ NMMA.

significantly (Fig. 6); however, L-NMMA or endothelin-1 antiserum alone did not affect portal pressure in the absence of ethanol (Figs. 3 and 5). The data suggest the possibility that, even with lower ethanol concentrations ( $\leq 10 \mathrm{mM}$ ) which do not cause a visible change in portal pressure, nitric oxide is involved in regulation of portal pressure: the vasodilating action of nitric oxide completely offsets the vasoconstrictive effect of ethanol at lower ethanol concentrations.

The endothelium-derived vasoactive substances endothelin- 1 and nitric oxide have been reported to play an important role in regulation of vascular tone (16-19), but very little is known about whether exogenous substances exert vasoactive effects via the same mechanism. Based on the current results, we propose that the vascular tone of the hepatic microvasculature in the presence of ethanol is regulated predominantly by the actions of endothelin- 1 and nitric oxide. The data from this study provide evidence that portal venous flow is regulated by

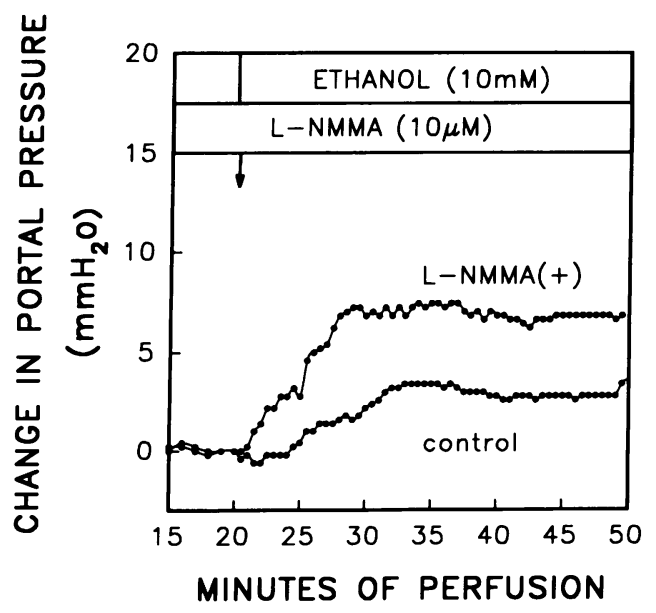

Figure 6. Time course of change in portal pressure during ethanol ( 10 $\mathrm{mM}$ ) infusion in the presence and absence of L-NMMA. Conditions are as described in Fig. $1 \mathrm{~A}$. $10 \mu \mathrm{M}$ L-NMMA was infused with 10 $\mathrm{mM}$ ethanol from $10 \mathrm{~min}$ before the initiation to the end of ethanol infusion. Values indicate means from five rats. the liver, although it has long been believed that in the presence of ethanol the liver cannot regulate portal venous blood flow and that any change that occurs is entirely passive $(31,32)$. Moreover, the idea that ethanol causes vasoconstriction through actions of two mediators, endothelin-1 and nitric oxide, may be applied to other organs, such as heart and brain, where ethanol is also known to induce vasoconstriction (2-4).

We have already shown that ethanol in higher concentrations caused decreased blood flow locally in the sinusoids (34), and this ethanol-induced perturbation of microcirculation can contribute to a pathogenesis of alcoholic liver damage $(5,6)$. A method to prevent the vasoconstricting effect of ethanol is expected to effectively reduce the incidence and morbidity of alcoholic liver injury. A modality of therapy that includes blockade of endothelin-1 action could provide a new strategy for prophylaxis and treatment of alcoholic organ damage.

\section{References}

1. Lieber, C. S. 1982. Medical Disorders of Alcoholism: Pathogenesis and Treatment. W. B. Sanders Company, Philadelphia. 1-589.

2. Altura, B. M., B. T. Altura, and A. Carella. 1983. Ethanol produces coronary vasospasm: evidence for direct action of ethanol on vascular muscle. $B r . J$. Pharmacol. 78:260-262.

3. Sharonne, N., M. D. Hayes, and A. A. Bove. 1988. Ethanol causes epicardial coronary artery vasoconstriction in the intact dog. Circulation. 78:165-170.

4. Altura, B. M., and B. T. Altura. 1983. Alcohol-induced spasm of cerebral blood vessels: relation to cerebrovascular accidents and sudden death. Science (Wash. DC). 220:331-333.

5. Hijioka, T., N. Sato, T. Matsumura, H. Yoshihara, Y. Takei, H. Fukui, M. Oshita, S. Kawano, and T. Kamada. 1991. Ethanol-induced disturbance of hepatic microcirculation and hepatic hypoxia. Biochem. Pharmacol. 41:15511557.

6. Oshita, M., N. Sato, H. Yoshihara, Y. Takei, T. Hijioka, H. Fukui, M. Goto, T. Matsunaga, T. Kashiwagi, S. Kawano, H. Fusamoto, and T. Kamada. 1992. Ethanol-induced vasoconstriction causes focal hepatocellular injury in the isolated perfused rat liver. Hepatology. 16:1007-1013.

7. French, S. W., N. C. Benson, and P. S. Sun. 1984. Centrilobular liver necrosis induced by hypoxia in chronic ethanol-fed rats. Hepatology. 4:912-917.

8. Miyamoto, K., and S. W. French. 1988. Hepatic adenine nucleotide metabolism measured in vivo in rats fed ethanol and a high fat-low protein diet. Hepatology. 8:53-60.

9. Nanji, A. A., L. T. Jui, and S. W. French. 1989. Effect of chronic carbon monoxide exposure on experimental alcoholic liver injury in rats. Life Sci. 45:885-890.

10. Tsukamoto, H., and X. P. Xi. 1989. Incomplete compensation of enhanced hepatic oxygen consumption in rats with alcoholic centrilobular liver necrosis. Hepatology. 9:302-306.

11. Yanagisawa, M., H. Kurihara, S. Kimura, Y. Tomobe, M. Kobayashi, Y. Mitsui, Y. Yazaki, K. Goto, and T. Masaki. 1988. A novel vasoconstrictor peptide produced by vascular endothelial cells. Nature (Lond.). 332:411-415.

12. Withrington, P. G., G. Nucci, and J. R. Vane. 1989. Endothelin-1 causes vasoconstriction and vasodilation in the blood perfused liver of the dog. J. Cardiovasc. Pharmacol. 13(Suppl. 5):S209-S210.

13. Gandhi, C. R., K. Stephenson, and M. S. Olson. 1990. Endothelin, a potent peptide agonist in the liver. J. Biol. Chem. 265:17432-17435.

14. Sakamoto, M. 1991. Effect of endothelin-1 on the contraction of Ito cells (fat-storing cells). Acta Hepatol. Jpn. 32:1027-1033.

15. Feelisch, M., and E. A. Noack. 1987. Correlation between nitric oxide formation during degradation of organic nitrates and activation of guanylate cyclase. Eur. J. Pharmacol. 139:19-30.

16. Rubanyi, G. M. 1991. Endothelium-derived relaxing and contracting factors. J. Cell. Biochem. 46:27-36.

17. Furchgott, R. F., and P. M. Vanhoutte. 1989. Endothelium-derived relaxing and contracting factors. FASEB (Fed. Am. Soc. Exp. Biol.) J. 3:2007-2018.

18. Luscher, T. F. 1989. Endothelium-derived relaxing and contracting factors: potential role in coronary artery disease. Eur. Heart J. 10:847-857.

19. Luscher, T. F., Z. Yang, M. Tschudi, L. Segesser, P. Stuiz, C. Boulanger, R. Siebebmann, M. Turina, and F. R. Buhler. 1990. Interaction between endothelin-1 and endothelium-derived relaxing factor in human arteries and vein. Circ. Res. 66:1088-1094.

20. Palmer, R. M. J., D. D. Rees, D. S. Ashton, and S. Moncada. 1988. L-arginine is the physiological precursor for the formation of nitric oxide in endothelium-dependent relaxation. Biochem. Biophys. Res. Commun. 153:1251-1256. 
21. Sholz, R., W. Hausen, and R. G. Thurman. 1973. Interaction of mixedfunction oxidation with biosynthetic processes. I. Inhibition of gluconeogenesis by aminopyrine in perfused rat liver. Eur. J. Biochem. 38:64-72.

22. Tsuji, S., S. Kawano, T. Michida, E. Masuda, K. Nagano, Y. Takei, H. Fusamoto, and T. Kamada. 1992. Ethanol stimulates immunoreactive endothelin-1 and -2 release from cultured human umbilical vein endothelial cells. Alcohol. Clin. Exp. Res. 16:347-349.

23. Rieder, H., G. Ramadori, and K. H. Meyer zum Buschenfelde. 1991 Sinusoidal endothelial liver cells in vitro release endothelin-augmentation by transforming growth factor $\beta$ and Kupffer cells-conditioned media. Klin. Wo chenschr. 69:387-391.

24. Hijioka, T., N. Sato, T. Matsumura, Y. Takei, H. Yoshihara, H. Eguchi, S. Kawano, and T. Kamada. 1988. Ethanol can be toxic to liver through microcirculatory disturbance. In Biomedical and Social Aspects of Alcohol and Alcoholism K. Kuriyama, A. Takada, and H. Ishii, editors. Excerpta Medica, Amsterdam, Holland. 401-404.

25. Friedman, S. L., D. C. Rockey, R. F. McGuire, J. J. Maher, J. K. Boyles and G. Yamasaki. 1992. Isolated hepatic lipocytes and Kupffer cells from norma human liver: morphological and functional characteristics in primary culture. Hepatology. 15:234-243.

26. Oda, M., N. Tsukada, N. Watanabe, H. Komatsu, Y. Yonei, and M. Tsuchiya. 1984. Functional implication of the sinusoidal endothelial fenestrae in the regulation of the hepatic microcirculation. Hepatology. 4:754. (Abstr.)
27. Pinzani, M., P. Failli, C. Ruocco, A., Casini, S. Milani, A. Giotti, and P. Gentilini. 1991. Fat-storing cells (FSC) as liver specific pericytes: spatial dynamics of agonist-stimulated intracellular calcium transients. Hepatology. 14:114A. (Abstr.)

28. Curran, R. D., T. R. Billiar, D. J. Steur, K. Hofmann, and R. L. Simmons. 1989. Hepatocytes produce nitrogen oxides from $L$-arginine in response to inflammatory products of Kupffer cells. J. Exp. Med. 170:1769-1774.

29. Jenkins, S. A., J. N. Baxter, P. Devitt, I. Taylor, and R. Shields. 1986. Effects of alcohol on hepatic hemodynamics in the rat. Digestion. 34:236-242.

30. Bravo, I. R., C. G. Acevdo, and V. Callards. 1980. Acute effects of ethano on liver blood circulation in anesthetized dog. Alcohol. Clin. Exp. Res. 4:248 253.

31. Bredfeldt, J. E., E. M. Riley, and R. J. Groszmann. 1985. Compensatory mechanisms in response to an elevated hepatic oxygen consumption in chronically ethanol-fed rats. Am. J. Physiol. 248:G507-G511.

32. Verma-Ansil, B., F. J. Carmichael, V. Saldivia, G. Varghese, and H. Orrego. 1989. Effect of ethanol on splanchnic hemodynamics in awake and unrestrained rats with portal hypertension. Hepatology. 10:946-952.

33. Kawasaki, T., F. J. Carmichael, V. Saldivia, L. Roldon, and H. Orrego. 1990. Relationship between portal venous and hepatic arterial blood flows: spectrum of response. Am. J. Physiol. 259:G1010-1018.

34. Eguchi, H., N. Sato, T. Matsumura, S. Kawano, and T. Kamada. 1988. In vivo estimation of oxygen saturation of hemoglobin in hepatic lobules in rats. Adv. Exp. Med. Biol. 222:591-596. 